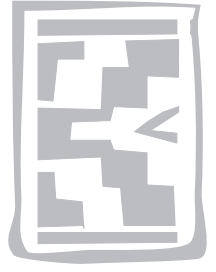

\title{
Detection of natural Trypanosoma vivax infections in pigs with microhaematocrit centrifugation and amplification of ITS1 rDNA
}

\author{
S. BIRYOMUMAISHO ${ }^{1 *}$, S.E. MELVILLE² ${ }^{2}$ E. KATUNGUKA-RWAKISHAYA ${ }^{1}$ and G.W. LUBEGA ${ }^{3}$
}

\begin{abstract}
BIRYOMUMAISHO, S., MELVILLE, S.E., KATUNGUKA-RWAKISHAYA, E. \& LUBEGA, G.W. 2009. Detection of natural Trypanosoma vivax infections in pigs with microhaematocrit centrifugation and amplification of ITS1 rDNA. Onderstepoort Journal of Veterinary Research, 76:285-289

Different species of trypanosomes may infect their mammalian hosts both singly or in combination. This study was undertaken to determine the trypanosome species that may be afflicting pigs in Uganda. Blood was collected from pigs of all ages and sexes from two districts, Kasese in Western and Jinja in Central Uganda. Of the 133 pig blood samples from Kasese that were tested for trypanosomes using the microhaematocrit centrifugation technique (MHCT), none was found to be infected. However, of the 253 pigs from Jinja district, nine were infected with trypanosomes of which three had T. vivax as determined by MHCT. However, application of the ITS1 rDNA PCR test revealed that eight pigs had $T$. vivax in mixed infections and one pig had $T$. vivax monolithic infection. These observations show that under certain circumstances, pigs may be important reservoirs for, as well as hosts to, T. vivax, contrary to earlier reports.
\end{abstract}

Keywords: ITS-PCR, pigs, Trypanosoma vivax, Uganda

\section{INTRODUCTION}

Trypanosomes remain a constant threat to the lives of humans, cattle and other domesticated animals, throughout large regions of Africa and South America. In Africa, the disease in domestic animals is mainly caused by $T$. congolense and $T$. vivax, with $T$. congolense being the most pathogenic species in East Africa and T. vivax in West Africa (Kaaya, Winqvist \& Johnson 1977). Methods of screening ani-

* Author to whom correspondence is to be directed. E-mail: biryomumaisho@ vetmed.mak.ac.ug

1 Department of Veterinary Medicine, Makerere University, P.O. Box 7062, Kampala, Uganda

2 Department of Pathology, University of Cambridge, Cambridge, CB2 1QP, UK. Present address: Hughes Hall, University of Cambridge, Cambridge, CB1 2EW, UK

3 Department of Veterinary Parasitology and Microbiology, Makerere University, P.O. Box 7062, Kampala, Uganda

Accepted for publication 19 February 2009-Editor mals for trypanosomosis for epidemiological studies include direct microscopic observation of parasites in the buffy coats following concentration of blood using the microhaematocrit centrifugation technique (MHCT), or serological tests that include the complement fixation test and the card agglutination test (Claes, Ilgekbayeya, Verloo, Saidouldin, Geerts, Buscher \& Goddeeris 2005). However, recently a variety of polymerase chain reaction (PCR)-based techniques have been proposed. Unlike the serological tests, PCR methods have largely overcome difficulties of sensitivity and specificity associated with direct parasite examination.

A number of PCR primers have been developed for detection of species and subspecies of $T$. congolense (Savannah) (Masiga, Smyth, Hayes, Bromidge \& Gibson 1992); T. congolense (Kilifi) (Masiga et al. 1992) and T. vivax (Masake, Majiwa, Moloo, Makau, Njuguna, Maina, Kabata, Jole-MoiYoi, \& Nantulya 1994). Since these are species-specific tests, sev- 
eral primer sets would be required to test each sample for all species of trypanosomes. Attempts have been made to develop a single molecular marker to accurately distinguish between species in a single PCR test using the internal transcribed spacers (ITS) located within the ribosomal RNA genes, both for trypanosomes and a number of other organisms (Schlotter, Hauser, von Haeseler \& Tautz 1994) and Samuel (1998).

The internal transcribed spacer (ITS) region of ribosomal DNA ( $\mathrm{rDNA}$ ) is a popular target for universal and specific trypanosome identification because of its highly conserved flanking regions, and size variability among trypanosome species and subgroups (Hernandez, Martin-Parras, Martinez-Robles \& Schvartzman 1993). A suitable ITS primer set for trypanosomes (KIN 1 and KIN 2) was developed by McLaughlin, Ssenyonga, Nanteza, Rubaire, Wafula, Hansen, Vodkin, Novak, Gordon, MontenegroJames, Mdachi, Sharipo, Chang \& Kakoma (1996) and subsequently was evaluated by Desquesnes, McLaughlin, Zoungrana \& Davila (2001) but the detection of $T$. vivax with these primers was less sensitive. Subsequently, Njiru, Constantine, Guya, Crowther, Kiragu, Thomson \& Davila (2005) evaluated new primers (CF and BR) for ITS 1 rDNA; these primers showed $100 \%$ homology with $T$. vivax rDNA sequence in GenBank, accession number U22316.

It has been proposed previously that the principal hosts of $T$. vivax are cattle, sheep, goats, horses and camels, but not dogs and pigs (Losos 1986). Stephen (1986) suggested that pigs are refractory to $T$. vivax infection since when he challenged pigs with wild-caught tsetse flies infected with $T$. vivax and $T$. congolense in a ratio 2:1, no $T$. vivax parasites were subsequently detected in the blood of these animals. However, a recent study by $\mathrm{Ng}$ 'ayo, Ngiru, Eucharia, Muluvi, Osir \& Masiga (2005) in western Kenya showed that pigs can, indeed, be infected with $T$. vivax. In their study intended to determine the animal reservoirs of human sleeping sickness, of the ten pigs infected with trypanosomes, three carried $T$. brucei and five had $T$. vivax. Similarly, in a study of trypanosome molecular differential diagnosis in livestock in South Western Uganda, Balyeidhusa, Enyaru, Matovu, Nerima, Akol \& Sebikali (2006) detected three T. vivax infections in 22 pigs.

The present study, therefore, was designed to conduct further investigations of the trypanosome species that affect pigs reared in two distinct agroecological zones in Uganda.

\section{MATERIALS AND METHODS}

\section{Collection and handling of pig blood samples}

Blood was collected from pigs of all ages and both sexes on smallholder farms in the districts of Western (Kasese) and Central (Jinja) Uganda. Fewer pigs than cattle were kept by farmers in the two districts; therefore, all pigs that were reared in villages where the cattle and goats were bled, were also bled. A total of 133 and 253 pigs were bled from Kasese and Jinja districts, respectively. In larger pigs (weighing more than $50 \mathrm{~kg}$ ) blood was obtained from the marginal ear vein and in smaller pigs, from the anterior vena cava or the cutaneous abdominal vein. Two to five millilitres of blood were dispensed into EDTA-coated collection tubes. Of this blood, $20 \mu \ell$ was spotted onto Whatman FTA cards. The remaining blood was used for preparation of microhaematocrit tubes for subsequent centrifugation and examination for trypanosomes as described by Murray, Murray \& Mclntyre (1977).

\section{Speciation of trypanosomes with microhaematocrit centrifugation/dark ground microscopy technique (MHCT)}

Capillary tubes were centrifuged at $1020 \mathrm{~g}$ for $5 \mathrm{~min}$ and the presence of trypanosomes detected by observation of parasite motion just above the buffy coat. In a sample where trypanosomes were detected, the microhaematocrit tube was cut just below the buffy coat to include $1 \mathrm{~mm}$ of the erythrocyte layer, and the contents including about $1 \mathrm{~cm}$ of plasma were transferred to a glass slide and covered with a cover slip. The wet smear was observed for trypanosomes under the microscope with reduced illumination and classified into species basing on their movements whereby $T$. congolense vibrates without progressing, $T$. brucei swims and $T$. vivax moves fast across the field (Radostatis, Gay, Blood \& Hinchcliff 2000).

\section{Extraction of DNA from blood spotted on FTA cards}

In this study, DNA was extracted from trypanosomepositive pigs because we intended to identify samples for further molecular studies (results not presented in this paper). DNA was extracted from dry blood spotted on FTA cards using the QIAamp ${ }^{\circledR}$ mini kit (2003) protocol and subsequently used for speciation of infecting trypanosomes by PCR amplification of ITS1 rDNA. Briefly, three or four $2 \mathrm{~mm}$ diameter circles of whole dried blood spot were punched out of the FTA cards and placed in a $1.5 \mathrm{ml}$ 
microfuge tube, covered with cell lysis buffer and incubated at $85^{\circ} \mathrm{C}$ for $10 \mathrm{~min}$. Genomic DNA was extracted by adding proteinase $\mathrm{K}$ and incubating the extract at $56^{\circ} \mathrm{C}$ for $1 \mathrm{~h}$. The DNA was precipitated with ethanol and subsequently eluted in $110 \mu \ell$ of buffer $\mathrm{AE}$, aliquoted and stored at $-20^{\circ} \mathrm{C}$ until required for use as template DNA for testing individual DNA extracts for infecting trypanosome species by ITS1 rDNA PCR.

\section{Amplification of the rDNA intergenic sequence by the polymerase chain reaction (ITS1-PCR)}

The $25 \mu \ell$ total volume PCR mix contained $2.5 \mu \ell$ of 10x PCR buffer ( $15 \mathrm{mM} \mathrm{MgCl}_{2}, 0.25 \mu$ of each $10 \mathrm{mM}$ dNTP solution), $0.5 \mu \ell$ containing $10 \mathrm{mM}$ (10x mixture) of the forward and reverse ITS1 rDNA primers, $0.125 \mu \ell$ of HotStar Taq DNA polymerase and $5 \mu \ell$ of the DNA extracted from FTA blood spots. The ITS1 rDNA primers used were:

- Forward (CF) 5'CCGGAAGTTCACCGATATTG

- Reverse (BR), 5'TTGCTGCGTTCTTCAACGAA

Reactions were performed in a PTC-100 Peltier Thermal Cycler which was programmed as follows: lid preheating at $96^{\circ} \mathrm{C}$ for $15 \mathrm{~min}$, followed by 38 cycles each consisting of denaturation at $94^{\circ} \mathrm{C}$ for $30 \mathrm{~s}$, annealing at $56^{\circ} \mathrm{C}$ for $1 \mathrm{~min}$ and extension at $72{ }^{\circ} \mathrm{C}$ for $90 \mathrm{~s}$. The mixture was incubated at $72^{\circ} \mathrm{C}$ for $10 \mathrm{~min}$ for the final extension step. The products were left at $4{ }^{\circ} \mathrm{C}$ in the thermocycler pending electrophoresis in a $1.5 \%$ agarose gel containing $0.5 \mu \mathrm{g} / \mathrm{ml}$ ethidium bromide and flooded with 1x TBE buffer. Electrophoresis was performed at $55 \mathrm{~V}$ for $30 \mathrm{~min}$.

\section{The positive control trypanosome DNA}

The T. brucei positive control DNA was extracted from the procyclic form of strain 927 (T. brucei TREU
927/4 PAL/KE/70/EATRO 1534). Trypanosoma congolense and $T$. vivax DNA were extracted from strains IL 3000 and IL 2569, respectively, which were kindly provided by Dr Phelix Majiwa.

\section{RESULTS}

\section{Identification of infecting trypanosomes using MHCT and ITS1 rDNA PCR}

The results of MHCT trypanosome speciation from pig blood samples (Table 1) based on movement characteristics of trypanosomes showed three species, namely, $T$. brucei, $T$. congolense and $T$. vivax. The movement characteristics of trypanosomes from pig no. 128 were not characteristic of any of the three species; hence the infecting trypanosomes species were not assigned. All infections were confirmed by re-testing with ITS1 rDNA PCR.

Species identification using the ITS1 rDNA PCR analysis detected more species of trypanosomes in individual samples compared to the MHCT except for pig number 164. Trypanosoma vivax was detected by both techniques; $T$. brucei was the most common trypanosome and was detected in eight of the nine samples by ITS1 rDNA PCR, mainly in mixed infections. The MHCT detected only three mixed infections compared to eight with the molecular technique.

Determination of the trypanosome species by PCR analysis was achieved by comparing individual PCR amplicons with the corresponding band size of the positive control (Tb, Tc and Tv) bands (Fig. 1). Presence of more than one band denoted presence of mixed trypanosome infections while single bands denoted monolithic infections. Of the nine pig samples, three showed banding patterns corresponding

TABLE 1 Speciation of trypanosomes isolated from pigs in Jinja district

\begin{tabular}{|c|c|c|}
\hline \multirow{2}{*}{ Pig identity } & \multicolumn{2}{|l|}{ Trypanosome species } \\
\hline & Ву МНСТ & By PCR of ITS1 rDNA \\
\hline $123^{*}$ & T. brucei & T. brucei, $T$. congolense, $T$. vivax \\
\hline 124 & T. congolense & T. brucei, T. congolense, T. vivax \\
\hline 128 & Not classified & T. brucei, T. vivax \\
\hline 132 & T. brucei, T. congolense & T. brucei, T. congolense, $T$. vivax \\
\hline 146 & T. brucei & T. brucei, T. congolense \\
\hline 147 & T. vivax & T. brucei, T. vivax \\
\hline 148 & T. brucei & T. brucei, T. vivax \\
\hline 162 & T. vivax, T. brucei & T. brucei, T. vivax \\
\hline 164 & T. brucei, T. vivax & T. vivax \\
\hline
\end{tabular}

* The numbers identifying pigs were assigned in the order pigs were bled. The figures do not represent identification tags of pigs 


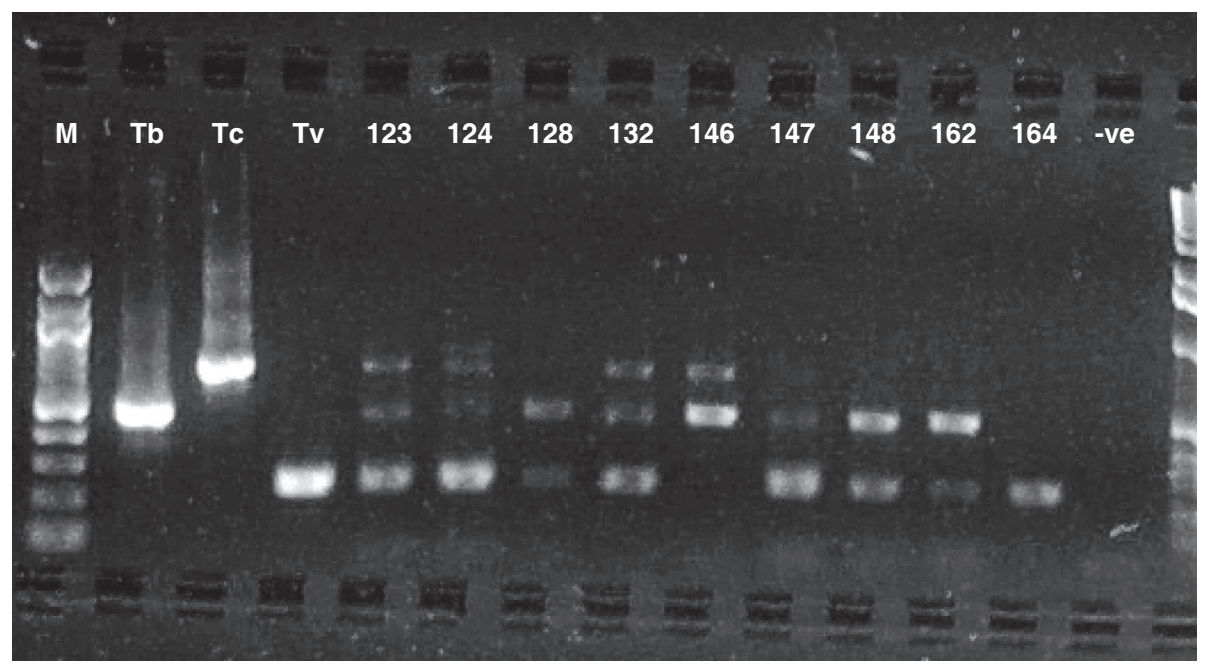

FIG. 1 Agarose gel $(1.5 \% \mathrm{w} / \mathrm{v})$ banding pattern after amplification of ITS1 rDNA of trypanosomes from pigs bled in Jinja district, central Uganda. $\mathrm{M}=$ Lambda ladder size marker (100 base pairs); $\mathrm{Tb}=T$. brucei; $\mathrm{Tc}=T$. congolense; $\mathrm{Tv}=T$. vivax; -ve = negative control (i.e. containing no DNA). The numbers assigned to each amplified DNA sample on the gel reflect the order in which pigs were bled

to mixed trypanosome infections comprising of $T$. vivax, T. congolense and T. vivax, four had T. vivax and T. brucei; one T.brucei and T. congolense while one is $T$. vivax monolithic infection.

The band sizes for ITS1 rDNA PCR amplicons from the control samples of trypanosome DNA and also trypanosome DNA extracted from the animal hosts correspond approximately to those given by Njiru et al. (2005). They reported that members of subgenus Trypanozoon (T. brucei brucei; T. evansi, T. $b$. rhodesiense and $T$. b. gambiense) gave a constant product of approximately 480 base pair (bp); T. congolense (Savannah) 700 bp, T. congolense (Kilifi) $620 \mathrm{bp}$; T. congolense (Forest) $710 \mathrm{bp}$ and $T$. vivax $250 \mathrm{bp}$.

Although agarose gels as used here cannot unequivocally resolve band sizes that vary by less than $100 \mathrm{bp}$ (to distinguish between the $T$. congolense subgroups), Fig. 1 clearly shows that each band obtained from the Ugandan isolates corresponded in size with one of the positive control samples.

\section{DISCUSSION}

The lack of sensitive and suitable diagnostic tests hinders the collection of accurate epidemiological data and institution of control programmes for livestock diseases. This study focused on accurate detection of parasites and how various species of trypanosomes could simultaneously be detected from blood samples of porcine hosts. Notable was the detection of $T$. vivax in pigs that have hitherto been reported to be refractory to the infection.

There have been previous reports of $T$. vivax not being a parasite of pigs (Losos 1986; Stephen 1986; Desquesnes \& Davilla 2002), but rather of cattle as the principal hosts. Recent advances in diagnostics, especially PCR-based techniques, have yielded different results showing that $T$. vivax can infect pigs, and suggesting it could be a causal organism of disease in pigs. The detection of natural T. vivax infections in pigs by both parasitological (MHCT) and molecular (ITS1 rDNA-PCR) techniques in the present study indicates that pigs do serve as hosts to $T$. vivax. The unique conditions under which infection and transmission occur are yet to be established. This finding is in agreement with Ng'ayo et al. (2005) who detected more significant $T$. vivax infections in goats and pigs than in sheep. Subsequently, Balyeidhusa et al. (2006) reported three $T$. vivax infections in pigs by ITS-PCR. While the presence of parasites in animal hosts may not necessarily lead to serious disease, it is important to determine whether pigs are significant hosts to $T$. vivax since control of livestock trypanosomosis usually targets cattle.

To date, pigs have always been excluded from trypanosomosis control exercises (personal observations), but these data suggest it may be necessary to treat pigs in areas where prevalence of cattle trypanosomosis is relatively high (exceeding 10 $\%$ prevalence). 
At present we do not know to what extent infection with $T$. vivax causes symptomatic disease in pigs. It is possible that pathology is less severe but that it plays a more important role as a reservoir for infection of tsetse and onward transmission to more susceptible species, thus aiding the maintenance of this parasite in the ecosystem. Future clinical pathology studies could be helpful in defining the importance of infection of pigs.

\section{ACKNOWLEDGEMENTS}

The authors thank the District Veterinary Officers of Kasese and Jinja districts for allowing us to utilize the district veterinary laboratories to process the blood samples. We also thank Innovations at Makerere (I@mak.com) for sponsoring the field study and the Association of Commonwealth Universities for financial support to Savino Biryomumaisho while at the Department of Pathology in the University of Cambridge.

\section{REFERENCES}

BALYEIDHUSA, A.S.P., ENYARU, J.C.K., MATOVU, E., NERIMA, B., AKOL, M. \& SEBIKALI, C. 2006. Molecular differential diagnosis of African trypanosomosis in domestic animals in North West Uganda, in Proceedings of the $11^{\text {th }}$ International Congress of Parasitology, Glasgow, Medimond, 2006: 7-12.

CLAES F., ILGEKBAYEYA, G.D., VERLOO, D., SAIDOULDIN, T.S., GEERTS, S., BUSCHER, P. \& GODDEERIS, B.M. 2005. Comparison of serological tests for equine trypanosomosis in naturally infected horses from Kazakhstan. Veterinary Parasitology, 131:221-225.

DESQUESNES, M. \& DÁVILA, A.M.R. 2002. Applications of PCR-based tools for detection and identification of animal trypanosomes: a review and perspectives. Veterinary Parasitology, 109:213-231.

DESQUESNES, M., MCLAUGHLIN, G., ZOUNGRANA, A. \& DÁVILA, A.M.R. 2001. Detection and identification of Trypanosoma of African livestock through a single PCR based on internal transcribed spacer 1 of rDNA. International Journal of Parasitology, 31:610-614.

KAAYA, G.P., WINQVIST, G. \& JOHNSON, L.W. 1977. Clinicopathological aspects of Trypanosoma congolense infection in goats. Bulletin of Animal Health and Production in Africa, 25:397-408.

HERNANDEZ, P., MARTIN-PARRAS, L., MARTINEZ-ROBLES, M.L. \& SCHVARTZMAN, J.B. 1993. Conserved features in the mode of replication of eukaryotic ribosomal RNA genes. EMBO Journal, 12:1475-1485.

LOSOS, G.J. 1986. Infectious tropical diseases of domestic animals. Protozoal diseases. Avon, UK: The Bath Press.

MASAKE, R.A., MAJIWA P.A., MOLOO, S.K., MAKAU, J.M., NJUGUNA J.T., MAINA, M., KABATA JOLE-MOIYOI, O.K. \& NANTULYA, V.M. 1994. Sensitive and specific detection of Trypanosoma vivax using the Polymerase Chain Reaction. Experimental Parasitology, 85:193-205.

MASIGA, D.K., SMYTH, A.J., HAYES, P., BROMIDGE, T.J. \& GIBSON, W.C. 1992. Sensitive detection of trypanosomes in tsetse flies by DNA amplification. International Journal of Parasitology, 64:207-218.

MCLAUGHLIN, G., SSENYONGA, S., NANTEZA, A., RUBAIRE, A., WAFULA, O., HANSEN, R.D., VODKIN, M., NOVAK, R.J., GORDON, V.R., MONTENEGRO-JAMES, S., MDACHI, M.R., SHAPIRO, S., CHANG, K.P. \& KAKOMA, I. 1996. PCRbased detection and typing of parasites, in Parasitology for the $21^{\text {st }}$ century, edited by M. Azcel \& M.Z. Alkan. Wallingford, Oxon: CAB International.

MURRAY, M., MURRAY, P.K. \& MCINTYRE, W.I.M. 1977. An improved parasitological technique for the diagnosis of African trypanosomosis. Transactions of the Royal Society of Tropical Medicine and Hygiene, 71:325-326.

NG'AYO, M.O., NJIRU, Z.K., EUCHARIA, U.K., MULUVI, G.M., OSIR, E.O. \& MASIGA, D.K. 2005. Detection of trypanosomes in small ruminants and pigs in western Kenya: important reservoirs in the epidemiology of sleeping sickness. Kinetoplastic Biology and Disease, 4:5.

NJIRU, Z.K., CONSTANTINE, C.C., GUYA, S., CROWTHER, J., KIRAGU, J.M., THOMPSON, R.C.A. \& DAVILA, A.M.R. 2005. The use of ITS1 rDNA PCR in detecting pathogenic African trypanosomes. Parasitology Research, 95:186-192.

RADOSTATIS, O.M., GAY, C., BLOOD, D.C. \& HINCHCLIFF, K.W. 2000. Diseases caused by Trypanosomes. Veterinary Medicine, $9^{\text {th }}$ ed. London: W.B. Saunders Company Limited.

SAMUEL, R.E.A. 1998. ITS sequences from nuclear rRNA suggest unexpected phylogenetic relationships between euromediterranean, East Asiatic and North Atlantic taxa of Quercus (Gagaceae). Plant Systematics and Evolution, 211: 129-139.

SCHLOTTERER, C., HAUSER, M.T., VON HAESELER, A. \& TAUTZ, D. 1994. Comparative evolutionary analysis of rDNA ITS regions in Drosophila. Molecular Biology and Evolution, 11:513-522.

STEPHEN, L.E. 1986. Trypanosoma vivax. Trypanosomiasis: a veterinary perspective, $1^{\text {st }}$ ed. Oxford: Pergamon Press. 